\title{
Toll-like receptor 4 rs11536889 is associated with angiographic extent and severity of coronary artery disease in a Chinese population
}

\author{
Dandan Sun ${ }^{1}$, Yupeng Wu ${ }^{2}$, Honghu Wang ${ }^{1}$, Hong Yan ${ }^{1}$, Wen Liu ${ }^{1}$ and Jun Yang ${ }^{1}$ \\ ${ }^{1}$ Department of Cardiovascular Ultrasound, The First Affiliated Hospital of China Medical University, Shenyang, China \\ 2 Department of Neurosurgery, The First Affiliated Hospital of China Medical University, Shenyang, China \\ Correspondence to: Jun Yang, email: yangjun@cmulh.com \\ Keywords: TLR4; polymorphism; coronary artery disease; extent and severity; Pathology Section \\ Received: August 12,2016 Accepted: December 07, $2016 \quad$ Published: December 18, 2016
}

\section{ABSTRACT}

Toll-like receptor 4 (TLR4) is a key modulator in many inflammation-related diseases. Polymorphisms in the TLR4 gene may alter TLR4 expression and affect the extent and severity of coronary artery disease (CAD). We analyzed 3 polymorphisms of TLR4 in 607 Chinese subjects who underwent coronary arteriography. Blood samples were collected to identify the polymorphisms. We evaluated the relationships between the polymorphisms and the number of vessels involved in coronary stenosis, Gensini scores, and Duke prognostic scores. We found that rs11536889 was associated with an increased risk of 3-vessel disease. When subjects with 3-vessel disease were compared to subjects with nonsignificant CAD, rs11536889 variant genotypes were associated with an increased risk of 3-vessel disease (GC/CC vs. GG: $O R=2.06,95 \% C I=1.21-3.51)$. When subjects with 3 -vessel disease were compared to subjects with 1-vessel disease, rs11536889 variant genotypes were associated with an increased risk of 3-vessel disease (GC vs. GG: OR=2.14, $95 \% \mathrm{CI}=1.20-3.79$; $\mathrm{GC} / \mathrm{CC}$ vs. GG: $\mathrm{OR}=2.06,95 \% \mathrm{CI}=1.20-3.54)$. When subjects with 3 -vessel disease were compared to subjects with non-3-vessel disease, rs11536889 variant genotypes were associated with an increased risk of 3-vessel disease (GC vs. GG: OR=1.76, $95 \% \mathrm{CI}=1.12-2.75 ; \mathrm{GC} / \mathrm{CC}$ vs. GG: $\mathrm{OR}=1.83,95 \% \mathrm{CI}=1.19-2.82)$. The $T L R 4 \mathrm{rs} 11536889$ polymorphism was also related to Gensini score $(P=0.02)$. The Gensini score was higher in subjects with the variant $\mathrm{CC}$ and $\mathrm{GC} / \mathrm{CC}$ genotype than in subjects with the wild GG genotype (61.28 1.84 and $57.64 \pm 34.82$ vs. $51.27 \pm 34.57)$. Our results demonstrate that TLR4 rs11536889 polymorphism is a novel genetic factor in the development of CAD, influencing the extent and severity of CAD.

\section{INTRODUCTION}

Coronary artery disease (CAD) is a leading cause of death worldwide. The extent and severity of CAD is correlated with mortality and longevity [1]. Substantial clinical data have illustrated that inflammation is an important etiological mechanism underlying CAD and contributes to the extent and severity of the disease [2].

Toll-like receptor (TLR) 4 is one of the most wellcharacterized inflammation-related molecules in the immune system; it is closely related to the extent and severity of CAD. Mizoguchi et al showed that TLR4 expression on peripheral venous blood monocytes was positively correlated with Gensini score in a CAD population [3]. Multiple studies have shown that TLR2 and TLR4 are upregulated in atherosclerotic plaques and circulating monocytes and that this enhanced expression is associated with more severe atherosclerotic diseases [46]. Moreover, the expression of inflammatory cytokines induced by TLR4 is significantly related to the degree of coronary stenosis within CAD patient groups [7].

As it is known, sequence variants especially the single nucleotide polymorphisms (SNPs) in the promoter region, may change the binding capacity of certain transcription factors, such as $\mathrm{Sp} 1$, or $\mathrm{Nrf2}[8,9]$. Variants in the 3'-untranslated region (3'-UTR) may affect mRNA stability. All the above has hold great promise for altering TLR4 transcription, and thus modulating disease 
Table 1: Patient characteristics by the number of vessels involved in coronary stenosis.

\begin{tabular}{|c|c|c|c|c|c|c|}
\hline \multirow{2}{*}{ Variable } & \multirow{2}{*}{$\begin{array}{l}\text { Total } \\
\mathrm{n}=607\end{array}$} & \multirow{2}{*}{$\begin{array}{c}\text { Nonsignificant CAD } \\
n=186\end{array}$} & \multirow{2}{*}{$\begin{array}{c}\text { 1-vessel disease } \\
n=169\end{array}$} & \multirow{2}{*}{$\begin{array}{c}\text { 2-vessel disease } \\
\mathrm{n}=141\end{array}$} & \multicolumn{2}{|l|}{ 3-vessel disease } \\
\hline & & & & & $n=111$ & $P$ \\
\hline Male(\%) & $374(61.6)$ & $106(57.0)$ & $105(62.1)$ & $91(64.5)$ & $72(64.9)$ & 0.44 \\
\hline Female(\%) & $233(38.4)$ & $80(43.0)$ & $64(37.9)$ & $50(35.5)$ & $39(35.1)$ & 0.44 \\
\hline Age(years) & $59.44 \pm 9.80$ & $59.72 \pm 9.12$ & $56.78 \pm 9.65$ & $60.47 \pm 10.52$ & $61.68 \pm 9.41$ & $<0.01$ \\
\hline Dyslipidemia(\%) & $504(83.0)$ & $147(78.7)$ & $143(84.4)$ & $113(79.9)$ & $101(91.0)$ & 0.04 \\
\hline $\mathrm{CHO}(\mathrm{mmol} / \mathrm{L})$ & $4.14 \pm 1.08$ & $3.97 \pm 1.07$ & $4.23 \pm 0.99$ & $4.06 \pm 1.02$ & $4.33 \pm 1.27$ & 0.03 \\
\hline TRIGLY(mmol/L) & $1.77 \pm 1.20$ & $1.67 \pm 0.97$ & $1.83 \pm 1.23$ & $1.69 \pm 1.14$ & $1.89 \pm 1.44$ & 0.32 \\
\hline LDL-C(mmol/L) & $2.58 \pm 0.94$ & $2.47 \pm 0.94$ & $2.63 \pm 0.84$ & $2.50 \pm 0.94$ & $2.74 \pm 1.04$ & 0.08 \\
\hline HDL-C(mmol/L) & $1.03 \pm 0.28$ & $1.01 \pm 0.29$ & $1.07 \pm 0.30$ & $1.02 \pm 0.25$ & $1.01 \pm 0.24$ & 0.17 \\
\hline Hypertension(\%) & $420(69.1)$ & $111(59.2)$ & $118(69.7)$ & $104(73.8)$ & $87(78.4)$ & $<0.01$ \\
\hline $\mathrm{SBP}(\mathrm{mmHg})$ & $159.94 \pm 34.46$ & $151.58 \pm 33.71$ & $160.37 \pm 32.06$ & $165.12 \pm 37.91$ & $165.28 \pm 32.85$ & $<0.01$ \\
\hline $\mathrm{DBP}(\mathrm{mmHg})$ & $92.45 \pm 21.91$ & $88.76 \pm 22.45$ & $93.67 \pm 18.40$ & $92.99 \pm 24.79$ & $95.32 \pm 22.18$ & 0.06 \\
\hline $\operatorname{DM}(\%)$ & $210(34.6)$ & $54(29.0)$ & $51(30.2)$ & $48(34.0)$ & $57(51.4)$ & $<0.01$ \\
\hline Fasting glucose $(\mathrm{mmol} / \mathrm{L})$ & $6.38 \pm 1.99$ & $6.03 \pm 1.50$ & $6.30 \pm 1.87$ & $6.42 \pm 1.97$ & $7.04 \pm 2.67$ & $<0.01$ \\
\hline $2 \mathrm{~h}$ glucose $(\mathrm{mmol} / \mathrm{L})$ & $9.57 \pm 4.38$ & $8.72 \pm 3.41$ & $9.78 \pm 4.91$ & $9.13 \pm 4.19$ & $10.93 \pm 4.68$ & 0.01 \\
\hline Smoker(\%) & 231(37.9) & $67(36.2)$ & $61(36.1)$ & $54(38.6)$ & $49(44.1)$ & 0.44 \\
\hline Drinker(\%) & $102(16.5)$ & $37(20.0)$ & $27(16.0)$ & $18(12.8)$ & $20(18.0)$ & 0.29 \\
\hline \multicolumn{7}{|l|}{ Current medication use } \\
\hline Statin(\%) & $422(69.6)$ & $106(57.0)$ & $120(71.0)$ & 101(71.6) & $95(85.6)$ & $<0.01$ \\
\hline $\operatorname{ASA}(\%)$ & $355(58.5)$ & $73(39.0)$ & $102(60.6)$ & $92(65.2)$ & $88(78.9)$ & $<0.01$ \\
\hline $\operatorname{ACEI}(\%)$ & $319(52.5)$ & $84(45.2)$ & $90(53.3)$ & $77(54.6)$ & $72(64.8)$ & $<0.01$ \\
\hline
\end{tabular}

Values are $\mathrm{n}(\%)$ or mean \pm SD unless otherwise noted. CHO, cholesterol; TRIGLY, triglyceride; LDL-C, low-density lipoprotein cholesterol; HDL-C, high-density lipoprotein cholesterol; SBP, systolic blood pressure; DBP, diastolic blood pressure; DM, diabetes mellitus; ASA, acetylsalicylic acid; ACEI, angiotensin converting enzyme inhibitor.

susceptibility $[10,11]$. Several studies have revealed that TLR4 polymorphisms in the promoter region and 3'UTR are associated with various inflammation-related diseases. Zhang et al reported a positive association between asthma severity and the GG genotype of TLR4 rs10983755, which indicated that the variant A allele of rs 10983755 has a protective effect on asthma severity [12]. A study by Minmin et al reported that individuals carrying the heterozygous genotype for the rs 10116253 had a significantly decreased risk of hepatocellular carcinoma compared to those carrying the wild-type homozygous genotype [13]. Peng et al reported that the variant genotype of TLR4 rs11536889 was associated with an increased risk of type 2 diabetes mellitus (DM) in female subjects, as well as high levels of 2-hour plasma glucose and high-density lipoprotein cholesterol [14].

No genetic study has investigated the relationship between TLR4 polymorphisms in the promoter region and 3'-UTR and the extent and severity of CAD. In this study, we investigated the association between 3 tag-
SNPs, which capture essential genetic information about the promoter region and 3'-UTR of the TLR4 gene, and angiographically defined CAD severity and extent, from the number of vessels involved coronary stenosis, Gensini score to Duke prognostic score.

\section{RESULTS}

\section{Characteristics of the study population}

We included a total of 607 subjects who underwent coronary angiography in this study. The study population included 374 men (61.6\%) and 233 women (38.4\%). The mean age of the patients was $59.44 \pm 9.80$ years. Table 1 summarizes the characteristics of the subjects according to the number of vessels involved in coronary stenosis. In all, 106 subjects had nonsignificant CAD, 169 subjects had 1-vessel disease, 141 subjects had 2-vessel disease, 
Table 2: Patient characteristics by genotypes of TLR4 polymorphisms.

\begin{tabular}{|c|c|c|c|c|c|c|c|c|c|c|c|c|}
\hline \multirow{2}{*}{ Variable } & \multicolumn{4}{|c|}{ rs10116253 } & \multicolumn{4}{|c|}{ rs10983755 } & \multicolumn{4}{|c|}{ rs11536889 } \\
\hline & TT & TC & $\mathrm{CC}$ & $P$ & GG & GA & $\mathbf{A A}$ & $P$ & GG & GC & $\mathrm{CC}$ & $P$ \\
\hline Male $(\%)$ & $132(66.3)$ & $182(59.1)$ & $58(59.2)$ & 0.23 & $185(64.5)$ & $158(59.4)$ & $30(56.6)$ & 0.35 & $225(60.0)$ & $128(65.0)$ & $20(58.8)$ & 0.48 \\
\hline Female(\%) & $67(33.7)$ & $126(40.9)$ & $40(40.8)$ & 0.23 & $102(35.5)$ & $108(40.6)$ & $23(43.4)$ & 0.35 & $150(40.0)$ & $69(35.0)$ & $14(41.2)$ & 0.48 \\
\hline Age(years) & $59.23 \pm 9.87$ & $59.35 \pm 9.94$ & $60.03 \pm 9.36$ & 0.79 & $59.17 \pm 9.87$ & $59.68 \pm 9.81$ & $59.53 \pm 9.57$ & 0.83 & $59.27 \pm 9.68$ & $59.74 \pm 10.18$ & $59.29 \pm 9.19$ & 0.86 \\
\hline Dyslipidemia(\%) & $161(80.9)$ & $262(85.1)$ & $81(82.7)$ & 0.46 & $233(81.2)$ & $229(86.1)$ & $42(79.2)$ & 0.22 & $309(82.4)$ & $169(85.8)$ & $26(76.5)$ & 0.33 \\
\hline $\mathrm{CHO}(\mathrm{mmol} / \mathrm{L})$ & $4.05 \pm 0.96$ & $4.19 \pm 1.13$ & $4.19 \pm 1.15$ & 0.37 & $4.10 \pm 0.99$ & $4.18 \pm 1.16$ & $4.20 \pm 1.12$ & 0.61 & $4.107 \pm 1.05$ & $4.25 \pm 1.13$ & $4.27 \pm 1.10$ & 0.14 \\
\hline TRIGLY $(\mathrm{mmol} / \mathrm{L})$ & $1.81 \pm 1.14$ & $1.78 \pm 1.27$ & $1.67 \pm 1.08$ & 0.57 & $1.78 \pm 1.12$ & $1.81 \pm 1.35$ & $1.51 \pm 0.71$ & 0.25 & $1.81 \pm 1.21$ & $1.70 \pm 1.21$ & $1.77 \pm 0.98$ & 0.64 \\
\hline $\mathrm{LDL}-\mathrm{C}(\mathrm{mmol} / \mathrm{L})$ & $2.50 \pm 0.88$ & $2.62 \pm 0.94$ & $2.62 \pm 1.03$ & 0.32 & $2.54 \pm 0.88$ & $2.62 \pm 0.96$ & $2.58 \pm 1.06$ & 0.61 & $2.53 \pm 0.92$ & $2.66 \pm 0.95$ & $2.65 \pm 0.98$ & 0.27 \\
\hline $\mathrm{HDL}-\mathrm{C}(\mathrm{mmol} / \mathrm{L})$ & $1.02 \pm 0.29$ & $1.03 \pm 0.27$ & $1.04 \pm 0.26$ & 0.92 & $1.02 \pm 0.28$ & $1.03 \pm 0.28$ & $1.08 \pm 0.25$ & 0.33 & $1.03 \pm 0.29$ & $1.02 \pm 0.25$ & $1.07 \pm 0.30$ & 0.65 \\
\hline Hypertension(\%) & $141(70.9)$ & $211(68.5)$ & $67(68.4)$ & 0.84 & $201(70.0)$ & $182(68.4)$ & $36(67.9)$ & 0.90 & $259(69.1)$ & $142(72.1)$ & $18(52.9)$ & 0.08 \\
\hline $\mathrm{SBP}(\mathrm{mmHg})$ & $163.51 \pm 34.54$ & $159.11 \pm 33.42$ & $156.19 \pm 36.99$ & 0.18 & $162.28 \pm 33.55$ & $158.45 \pm 34.12$ & $155.40 \pm 40.40$ & 0.27 & $160.13 \pm 34.52$ & $161.28 \pm 35.21$ & $150.94 \pm 28.49$ & 0.27 \\
\hline $\mathrm{DBP}(\mathrm{mmHg})$ & $94.38 \pm 21.53$ & $92.27 \pm 22.36$ & $89.37 \pm 21.19$ & 0.17 & $94.54 \pm 21.43$ & $91.39 \pm 21.91$ & $89.60 \pm 23.56$ & 0.29 & $91.29 \pm 21.45$ & $94.49 \pm 22.77$ & $89.76 \pm 20.73$ & 0.29 \\
\hline $\mathrm{DM}(\%)$ & $70(35.2)$ & $98(31.8)$ & $42(42.9)$ & 0.13 & $106(36.9)$ & $82(30.8)$ & $22(41.5)$ & 0.14 & $130(34.7)$ & $68(34.5)$ & $12(35.3)$ & 0.99 \\
\hline Fasting glucose $(\mathrm{mmol} / \mathrm{L})$ & $6.45 \pm 1.82$ & $6.29 \pm 1.98$ & $6.52 \pm 2.35$ & 0.52 & $6.469 \pm 2.01$ & $6.21 \pm 1.74$ & $6.78 \pm 2.87$ & 0.12 & $6.37 \pm 2.02$ & $6.41 \pm 2.02$ & $6.24 \pm 1.42$ & 0.91 \\
\hline 2-hour glucose(mmol/L) & $9.67 \pm 4.47$ & $9.30 \pm 4.21$ & $10.28 \pm 4.73$ & 0.36 & $9.69 \pm 4.61$ & $9.40 \pm 4.16$ & $9.72 \pm 4.27$ & 0.84 & $9.89 \pm 4.62$ & $9.36 \pm 4.13$ & $7.69 \pm 2.61$ & 0.07 \\
\hline Smoking(\%) & $76(38.2)$ & $120(39.0)$ & $34(34.7)$ & 0.75 & $108(37.6)$ & $103(38.7)$ & $19(35.8)$ & 0.91 & $133(35.4)$ & $83(42.3)$ & $14(41.2)$ & 0.23 \\
\hline Drinking(\%) & $32(16.2)$ & $54(17.5)$ & $15(15.3)$ & 0.80 & $42(14.6)$ & $53(19.9)$ & $6(11.3)$ & 0.12 & $62(16.5)$ & $37(18.9)$ & $2(5.7)$ & 0.08 \\
\hline \multicolumn{13}{|l|}{ Current medication use } \\
\hline Statin(\%) & $145(72.9)$ & $209(67.5)$ & $68(68.7)$ & 0.73 & $214(74.6)$ & $171(63.4)$ & $38(9.6)$ & 0.68 & $265(70.6)$ & $138(70.0)$ & 19(55.9) & 0.23 \\
\hline ASA(\%) & $111(55.8)$ & $184(59.7)$ & $60(61.2)$ & 0.34 & $160(55.7)$ & $163(61.3)$ & $32(60.3)$ & 0.42 & $210(56.0)$ & $125(63.4)$ & $20(58.8)$ & 0.31 \\
\hline ACEI(\%) & $102(51.3)$ & $166(53.9)$ & $51(52.0)$ & 0.49 & $147(51.2)$ & $145(54.5)$ & $27(50.9)$ & 0.27 & $196(52.3)$ & $107(54.3)$ & $16(47.1)$ & 0.41 \\
\hline
\end{tabular}

Values are $\mathrm{n}(\%)$ or mean $\pm \mathrm{SD}$ unless otherwise noted. TLR4, toll-like receptor 4; Other abbreviations as in Table 1.

and 111 subjects had 3-vessel disease. Compared to subjects in other groups, subjects with 3-vessel disease had a higher prevalence of dyslipidemia, hypertension, DM, and current use of cardiovascular medication (e.g, statin, acetylsalicylic acid [ASA], and angiotension conversion enzyme inhibitor $[\mathrm{ACEI}])(P<0.05)$. Further, subjects with 3-vessel disease were older and had higher systolic blood pressure, total cholesterol levels, fasting plasma glucose levels, and 2-hour plasma glucose levels than subjects in other groups $(P<0.05)$. Sex, smoking status, and alcohol consumption were not different among different groups $(P>0.05)$.

Table S1 shows the distribution of TLR4 tagSNPs in the study population. The frequencies of each polymorphism within the population were in HardyWeinberg equilibrium (HWE) $(P>0.05)$. Table 2 displays the baseline clinical characteristics of the population according to genotype. No significant differences in traditional risk factors or laboratory parameters were observed among the genotype groups $(P>0.05)$.

\section{Effect of TLR4 polymorphisms on the number of vessels involved in coronary stenosis}

The odds ratios (ORs) and 95\% confidence intervals (CIs) for TLR4 tag-SNPs and the number of vessels involved in coronary stenosis are shown in
Table 3. We noted a significant association between the prevalence of 3-vessel disease and variant genotypes of TLR4 rs11536889. When subjects with 3-vessel disease were compared to subjects with nonsignificant CAD, rs11536889 variant genotypes were associated with an increased risk of 3-vessel disease (GC/CC vs. GG: OR = $2.06,95 \% \mathrm{CI}=1.21-3.51)$. When subjects with 3-vessel disease were compared to subjects with 1-vessel disease, rs11536889 variant genotypes were associated with an increased risk of 3-vessel disease (GC vs. GG: OR $=2.14$, $95 \% \mathrm{CI}=1.20-3.79$; GC/CC vs. GG: $\mathrm{OR}=2.06,95 \%$ $\mathrm{CI}=1.20-3.54)$. When subjects with 3 -vessel disease were compared to subjects with non-3-vessel disease, rs11536889 variant genotypes were associated with an increased risk of 3-vessel disease (GC vs. GG: OR $=1.76$, $95 \% \mathrm{CI}=1.12-2.75 ; \mathrm{GC} / \mathrm{CC}$ vs. $\mathrm{GG}: \mathrm{OR}=1.83,95 \% \mathrm{CI}$ $=1.19-2.82$ ). Variants in rs 10116253 and rs10983755 were not related to the number vessels involved in coronary stenosis $(P>0.05)$ (Tables S2 and S3).

\section{Effect of TLR4 polymorphisms on Gensini score}

Table 4 summarizes the results of TLR4 tag-SNPs association analyses with Gensini scores of CAD in the studied population. The Gensini score of subjects in the variant $\mathrm{CC}$ genotype group and the $\mathrm{GC} / \mathrm{CC}$ genotype group were greater than the score of subjects in the wild 
Table 3: Association between genotypes of TLR4 rs11536889 with the number of vessels involved in coronary stenosis

\begin{tabular}{|c|c|c|c|c|c|c|c|c|c|c|c|c|}
\hline \multirow{2}{*}{ Group } & \multicolumn{3}{|c|}{ GC vs. GG } & \multicolumn{3}{|c|}{ CC vs. GG } & \multicolumn{3}{|c|}{ GC/CC vs. GG } & \multicolumn{3}{|c|}{ CC vs. GC/GG } \\
\hline & OR(95\%CI) ${ }^{a}$ & $P^{\text {a }}$ & $P^{\mathrm{b}}$ & OR(95\%CI) ${ }^{a}$ & $P^{\mathrm{a}}$ & $P^{\mathrm{b}}$ & OR $(95 \% C I)^{a}$ & $P^{\mathrm{a}}$ & $P^{\mathrm{b}}$ & $\operatorname{OR}(95 \% \mathrm{CI})^{\mathrm{a}}$ & $P^{\text {a }}$ & $P^{\mathrm{b}}$ \\
\hline 1 -vessel disease vs. nonsignificant CAD & $0.75(0.46,1.20)$ & 0.23 & 0.68 & $2.61(0.88,7.75)$ & 0.08 & 0.25 & $0.87(0.56,1.36)$ & 0.54 & 0.99 & $2.53(0.86,7.46)$ & 0.09 & 0.28 \\
\hline 2-vessel disease vs. nonsignificant CAD & $0.81(0.50,1.32)$ & 0.40 & 0.99 & $2.21(0.65,7.51)$ & 0.21 & 0.62 & $0.90(0.56,1.43)$ & 0.64 & 0.99 & $2.05(0.62,6.77)$ & 0.24 & 0.71 \\
\hline 3-vessel disease vs. nonsignificant CAD & $1.93(1.11,3.37)$ & 0.02 & 0.06 & $2.77(0.89,8.65)$ & 0.08 & 0.24 & $2.06(1.21,3.51)$ & 0.01 & 0.02 & $2.23(0.74,6.70)$ & 0.15 & 0.46 \\
\hline 2-vessel disease vs. 1 -vessel disease & $1.12(0.67,1.89)$ & 0.66 & 0.99 & $0.82(0.30,2.24)$ & 0.69 & 0.99 & $1.06(0.65,1.73)$ & 0.81 & 0.99 & $0.78(0.29,2.09)$ & 0.62 & 0.99 \\
\hline 3-vessel disease vs. 1-vessel disease & $2.14(1.20,3.79)$ & 0.01 & 0.03 & $1.65(0.60,4.50)$ & 0.33 & 0.99 & $2.06(1.20,3.54)$ & 0.01 & 0.03 & $1.20(0.45,3.18)$ & 0.71 & 0.99 \\
\hline 3-vessel disease vs. 2-vessel disease & $1.44(0.85,2.43)$ & 0.17 & 0.52 & $3.90(1.15,13.24)$ & 0.03 & 0.09 & $1.59(0.96,2.63)$ & 0.07 & 0.21 & $3.13(0.96,10.25)$ & 0.06 & 0.18 \\
\hline 3-vessel disease vs. non 3-vessel disease & $1.76(1.12,2.75)$ & 0.01 & 0.04 & $2.57(1.07,6.17)$ & 0.03 & 0.10 & $1.83(1.19,2.82)$ & 0.01 & 0.02 & $1.96(0.84,4.55)$ & 0.12 & 0.35 \\
\hline
\end{tabular}

a, these tests were adjusted by age, sex, hypertension, diabetes mellitus, dyslipidemia, current medication use, smoking status and drinking status; ${ }^{\text {, }}$ P value was corrected by Bonferroni method; TLR4, toll-like receptor 4.

Table 4: Association of genotypes of TLR4 rs11536889 with Gensini Score and Duke prognostic score.

\begin{tabular}{|c|c|c|c|c|c|}
\hline \multirow{2}{*}{ Polymorphism } & \multirow{2}{*}{ Genotype } & \multicolumn{2}{|c|}{ Gensini score } & \multicolumn{2}{|c|}{ Duke prognostic score } \\
\hline & & $\operatorname{Mean} \pm$ SD & $\boldsymbol{P}$ & $\operatorname{Mean} \pm$ SD & $P$ \\
\hline \multirow[t]{4}{*}{ rs10116253 } & TT & $56.30 \pm 34.24$ & ref & $36.49 \pm 25.15$ & ref \\
\hline & $\mathrm{TC}$ & $51.27 \pm 34.24$ & 0.11 & $32.93 \pm 26.41$ & 0.13 \\
\hline & $\mathrm{CC}$ & $55.49 \pm 37.05$ & 0.85 & $34.31 \pm 26.11$ & 0.49 \\
\hline & $\mathrm{TC} / \mathrm{CC}$ & $52.35 \pm 34.98$ & 0.18 & $33.26 \pm 26.31$ & 0.15 \\
\hline \multirow[t]{4}{*}{ rs10983755 } & GG & $55.49 \pm 34.65$ & ref & $36.57 \pm 26.31$ & ref \\
\hline & GA & $51.77 \pm 35.15$ & 0.21 & $32.70 \pm 25.53$ & 0.10 \\
\hline & AA & $53.42 \pm 33.08$ & 0.69 & $35.47 \pm 25.18$ & 0.80 \\
\hline & GA/AA & $50.02 \pm 34.73$ & 0.22 & $34.32 \pm 25.47$ & 0.15 \\
\hline \multirow[t]{4}{*}{ rs11586889 } & GG & $51.27 \pm 31.84$ & ref & $32.50 \pm 25.11$ & ref \\
\hline & $\mathrm{GC}$ & $56.98 \pm 34.57$ & 0.10 & $36.14 \pm 27.03$ & 0.11 \\
\hline & $\mathrm{CC}$ & $61.28 \pm 35.31$ & 0.01 & $44.09 \pm 26.35$ & $\mathbf{0 . 0 3}$ \\
\hline & $\mathrm{GC} / \mathrm{CC}$ & $57.64 \pm 34.82$ & 0.03 & $37.31 \pm 27.02$ & 0.07 \\
\hline
\end{tabular}

TLR4, toll-like receptor 4.

GG genotype group $(61.28 \pm 31.84$ and $57.64 \pm 34.82 v s$. $51.27 \pm 34.57 ; P=0.01$ and 0.03 , respectively) (Figure 1). The association between rs11536889 and Gensini score remained significant after adjusting for other confounding factors $(P=0.02)$ (Table 5). TLR4 rs10116253 and rs10983755 were not significantly associated with Gensini score $(P>0.05)$ (Tables 4 and 5).

\section{Effect of TLR4 polymorphisms on Duke prognostic score}

TLR4 rs11536889 was associated with higher Duke prognostic score (Table 4). The highest Duke prognostic score was observed in subjects with the variant $\mathrm{GC}$ / CC genotype of TLR4 rs11536889 (44.09 \pm 26.35$)$; the lowest score was observed in subjects with the wild GG 
Table 5: Multivariate predictors of the extent and severity of CAD.

\begin{tabular}{|c|c|c|c|c|c|c|}
\hline \multirow{2}{*}{ Characteristic } & \multicolumn{3}{|c|}{ Log Gensini Score } & \multicolumn{3}{|c|}{ Log Duke Score } \\
\hline & B & SE & $P$ & B & SE & $\boldsymbol{P}$ \\
\hline Age (years) & 0.01 & 0.01 & 0.25 & 0.01 & 0.01 & 0.07 \\
\hline Sex & -0.10 & 0.03 & $<0.01$ & -0.03 & 0.02 & 0.25 \\
\hline Dyslipidemia & -0.01 & 0.04 & 0.74 & -0.03 & 0.03 & 0.26 \\
\hline Hypertension & -0.03 & 0.03 & 0.27 & -0.04 & 0.02 & 0.06 \\
\hline DM & -0.13 & 0.03 & $<0.01$ & -0.07 & 0.02 & $<0.01$ \\
\hline Smoker & -0.02 & 0.04 & 0.50 & -0.03 & 0.02 & 0.19 \\
\hline Drinker & 0.07 & 0.04 & 0.09 & 0.05 & 0.03 & 0.09 \\
\hline Statin use & -0.03 & 0.04 & 0.33 & -0.03 & 0.02 & 0.12 \\
\hline ASA use & -0.03 & 0.04 & 0.52 & -0.03 & 0.03 & 0.29 \\
\hline ACEI use & -0.02 & 0.03 & 0.81 & -0.03 & 0.03 & 0.29 \\
\hline TLR4 rs10116253 & 0.01 & 0.03 & 0.98 & -0.02 & 0.02 & 0.39 \\
\hline TLR4 rs10983755 & 0.01 & 0.03 & 0.96 & 0.02 & 0.02 & 0.33 \\
\hline TLR4 rs11536889 & -0.06 & 0.03 & 0.02 & -0.03 & 0.02 & 0.10 \\
\hline
\end{tabular}

TLR4, toll-like receptor 4; CAD, coronary artery disease; SNP, single nucleic polymorphism.

genotype of TLR4 rs11536889 (32.50 \pm 25.11$)(P=0.03)$. The association between rs 11536889 and Duke prognostic score became insignificant after adjusting for other confounding factors $(P>0.05)$ (Table 5). There were no relationships between TLR4 rs10116253 or rs10983755 and the Duke prognostic score $(P>0.05)$ (Tables 4 and 5).

\section{DISCUSSION}

This is the first study to report that a $3^{\text {'-UTR }}$
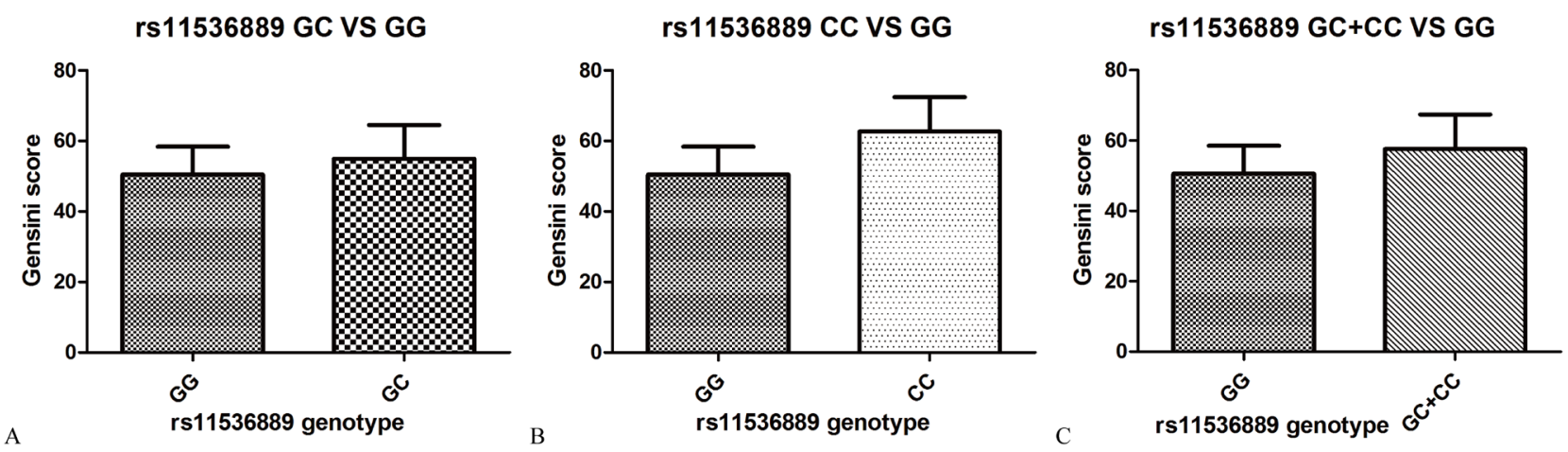

Figure 1: The extent and severity of CAD by TLR4 rs11536889 genotype. A. The Gensini score between GC and GG genotype. B. The Gensini score between CC and GG genotype. C. The Gensini score between GC/CC and GG genotype. $P$ value of log Gensini score and rs 11536889 is 0.02 . The model included age, sex, dyslipidemia, hypertension, DM, smoking status, alcohol consumption, current medication use, rs10116253, rs10983755 and rs11536889. The risk allele is C. CAD, coronary artery disease; TLR4, toll-like receptor 4; DM, diabetes mellitus. 
polymorphism (rs11536889) of TLR4 is related to the extent and severity of CAD. According to our data, subjects with variant genotypes of TLR4 rs11536889 had a higher risk of developing 3-vessel disease than the subjects with the wild-type genotype GG. We also noted a robust, direct relationship between variant genotypes of TLR4 rs11536889 and Gensini score.

TLR4 is involved in the inflammatory process, which plays a vital role in the progression of atherosclerotic cardiovascular disease. First, TLR4 can induce the proliferation of vascular smooth muscle cells and upregulate the expression of the elastin-degrading enzyme and cathepsin $\mathrm{S}$ that allow smooth muscle cells to migrate to the site of atherosclerosis $[15,16]$. Second, Vink et al found that stimulation of TLR4 on adventitial fibroblasts augmented neointima formation, an effect that was reduced in TLR4-defective mice by using a mouse femoral cuff model [17]. Third, several descriptive studies have showed that TLR4 is expressed by macrophages in murine and human lipid-rich atherosclerotic plaques [4, 18]. The activated TLR4 on macrophage can initiate a signal cascade that induces expression of inflammatory cytokines and proteases; this process may play a role in the formation and modeling of advanced atherosclerotic lesions [19].

In the present study, we demonstrated that TLR4 rs11536889 is associated with 3-vessel disease: the variant genotypes are risk factors for more extensive and severe CAD. Many previous studies have suggested that genetic variation of rs11536889 may influence human inflammation-related diseases [20-23]. The GC or CC genotypes of TLR4 rs11536889 have been associated with severe gastric atrophy in Japanese subjects who are Helicobacter pylori seropositive [20]. Castano-Rodriguez et al found that the TLR4 rs $11536889 \mathrm{C}$ allele was a risk factor for gastric cancer in Chinese subjects [21]. Wang et al found a trend toward a higher frequency of $\mathrm{GC} /$ $\mathrm{CC}$ genotypes in patients with sepsis, and the $\mathrm{C}$ allele was significantly associated with susceptibility to sepsis [22]. Another large study including 1383 prostate cancer patients and 780 age-matched controls in Sweden revealed that the frequencies of the variant genotypes of TLR4 rs11536889 were significantly higher in patients $(24.1 \%)$ than in controls $(19.7 \%)$ [23]. Until now, the correlation between TLR4 rs11536889 and CAD with multiple vessel involvement has not been evaluated. However, one study reported that the presence of the variant $\mathrm{C}$ allele of TLR4 rs11536889 loses a motif binding for hsamiR-1236 and hsa-miR-642a, which can specifically bind to target mRNA. This variant allele results in translational inhibition, thus increasing the expression of TLR4 [24]. Furthermore, peripheral blood mononuclear cells from the $\mathrm{CC}$ and GC subjects secreted higher levels of IL-8 in response to TLR4 ligand than the cells from the GG subjects [25]. Our results are consistent with the theory that TLR4 rs11536889 variant genotypes act as a risk factor for atherosclerosis development via increased TLR4 production. Therefore, our results raise the possibility that subjects with variant risk genotypes of TLR4 rs11536889 acquire a greater atheromatous burden in the development phase of CAD.

The Gensini score describes not only the number of stenosed vessels but also the percentage of narrowing of the major vessels and the anatomical location of the stenosis [26]. This score is often used for quantifying the extent and severity of CAD. Among the subjects in our population, we observed an association between TLR4 rs11536889 polymorphism and Gensini scores: the variant GC/CC genotypes of TLR4 rs11536889 were associated with a higher Gensini score. Several experimental studies have shown that altered production of TLR4 appears to be critical for the evolution and progression of the atherosclerotic process. Hollestelle et al evaluated TLR4 in a mouse model: after ligation of the femoral artery, they observed a paradoxical increase in wall thickness accompanied by a hyperplastic response of the arterial wall. This phenomenon was not detected in TLR4deficient mice [27]. Recently, Yin et al showed that TLR4 mediated intracellular lipid accumulation and ultimately led to foam cell formation by upregulating the expression of Acyl-coenzyme A: cholesterol acyltransferase 1, an intracellular enzyme that converts free cholesterol into cholesteryl esters for storage in lipid droplets [28]. The above evidence, together with our data, suggest the possibility that, in the process of atherosclerotic remodeling of adult human vessels, alterations in TLR4 production resulting from rs11536889 in the 3'-UTR of the TLR 4 gene could have substantial impacts on the extent and severity of CAD.

Our study has some potential limitations. First, the results of our study may be affected by selection bias. However, the genotype distribution of subjects was compatible with HWE. Second, the relatively small sample size may under power our results. Third, additional molecular biology studies evaluating the expression of TLR4 are necessary to identify the biological effect of the rs11536889 polymorphism of TLR4. Last, our study was performed in a Chinese Han population. Our findings should be confirmed in other geographic regions and ethnic groups.

In conclusion, in this cohort of 607 Chinese subjects with CAD, we demonstrated that variant genotypes of TLR4 rs11536889 were associated with an increased risk of developing 3-vessel disease and a higher Gensini score. TLR 4 rs 11536889 is a novel genetic factor in the development of CAD and significantly influences the extent and severity of CAD. 


\section{MATERIALS AND METHODS}

\section{Study population}

We enrolled 607 consecutive subjects who underwent coronary angiography at the First Affiliated Hospital of China Medical University between December 2012 and January 2016. This study was approved by the Ethics Committee of China Medical University, and carried out in accordance with the Declaration of Helsinki. Written informed consent was obtained from each subject. Subjects were excluded from participation if they had a history of percutaneous coronary intervention or coronary artery bypass surgery, a history of malignant disease, an autoimmune disease, or cardiomyopathy [29]. Clinical data included sex, age, hypertension, dyslipidemia, DM, current medication use (e.g., statins, ASA, and ACEIs), smoking status, and alcohol consumption. A "smoker" was defined as a subject who smoked at least one cigarette per day for more than one year; a "drinker" was defined as a subject who consumed at least one alcoholic drink per day for a minimum of 6 months.

\section{Angiography}

All of the coronary angiograms were reviewed by 2 experienced cardiologists who were both blinded to the genotype results. The extent and severity of CAD was estimated according to the results of the coronary angiography, including the number of vessels involved in the coronary stenosis and quantitative angiographic scores (i.e., Gensini score and Duke prognostic score). Detailed criteria for the evaluation methods are list in Table S4 [3032].

\section{Genotyping}

A 2-step approach, which has been described previously, was performed to identify the genotype of the 3 tag-SNPs [33]. Briefly, genomic DNA was obtained from peripheral blood using the standard phenol-chloroform method. Next, the polymorphisms were detected using the polymerase chain restriction-restriction fragment length polymorphism (PCR-RFLP) procedure. Table S5 lists the details of the PCR-RFLP conditions for the 3 tag-SNPs.

\section{Statistical analysis}

Continuous variables were presented as mean \pm standard deviation, and categorical variables were presented as numbers and percentages. Differences in baseline characteristics among groups were evaluated using analysis of variance (ANOVA), student's t-test, or the chi-square test. HWE in the study population was evaluated by the chi-square test.

The associations between the number of vessels involved in coronary stenosis (i.e., the proportions of patients with nonsignificant CAD, 1-vessel disease, 2-vessel disease, non-3-vessel disease, and 3-vessel disease) and TLR4 SNPs (i.e., variant heterozygote genotype, variant homozygote genotype, dominant model, and recessive model) were compared using multiple logistic regression tests. The models were adjusted according to sex, age, hypertension, dyslipidemia, DM, current medication use, smoking status, and alcohol consumption [34]. $P$ values were corrected for multiple comparisons using the Bonferroni method.

One-way ANOVA was used to determine the differences of quantitative angiographic scores among genotype groups. Logistic and linear regression models were constructed to test the additive effects of the SNPs on the extent and severity of CAD (i.e., log Gensini Score and log Duke score); each SNP was coded as 2, 1, or 0 according to the number of risk alleles. The model included age, sex, dyslipidemia, hypertension, DM, smoking status, alcohol consumption, current medication use, rs10116253. rs 10983755 and rs11536889 [35]. A 2 -tailed $P$ value less than 0.05 was considered significant. All statistical analyses were performed using SPSS 16.0 Software (Chicago, IL, USA).

\section{ACKNOWLEDGMENTS}

This work was supported partly by grants from the Natural Science Foundation of Liaoning Province (Ref No. 2015020506).

\section{CONFLICTS OF INTEREST}

All authors do not have a commercial or other association that might pose a conflict of interest.

\section{Author contributions}

D.D.S. and J.Y. participated in the study design and data interpretation. Y.W. and W.L participated in the sample collection. D.D.S., H.HW and H.Y. performed the DNA extraction and genotyping. D.D.S. and Y.P.W participated in the data analysis process and manuscript writing. All authors discussed the results and commented on the manuscript.

\section{REFERENCES}

1. Cassar A, Holmes DR, Jr., Rihal CS and Gersh BJ. Chronic coronary artery disease: diagnosis and management. Mayo Clinic proceedings. 2009; 84(12):1130-1146.

2. Biasucci LM, Liuzzo G, Della Bona R, Leo M, Biasillo G, 
Angiolillo DJ, Abbate A, Rizzello V, Niccoli G, Giubilato $\mathrm{S}$ and Crea F. Different apparent prognostic value of hsCRP in type 2 diabetic and nondiabetic patients with acute coronary syndromes. Clinical chemistry. 2009; 55(2):365368.

3. Mizoguchi E, Orihara K, Hamasaki S, Ishida S, Kataoka T, Ogawa M, Saihara K, Okui H, Fukudome T, Shinsato T, Shirasawa T, Ichiki H, Kubozono T, Ninomiya Y, Otsuji Y and Tei C. Association between Toll-like receptors and the extent and severity of coronary artery disease in patients with stable angina. Coronary artery disease. 2007; 18(1):3138.

4. Edfeldt K, Swedenborg J, Hansson GK and Yan ZQ. Expression of toll-like receptors in human atherosclerotic lesions: a possible pathway for plaque activation. Circulation. 2002; 105(10):1158-1161.

5. Ishikawa Y, Satoh M, Itoh T, Minami Y, Takahashi Y and Akamura M. Local expression of Toll-like receptor 4 at the site of ruptured plaques in patients with acute myocardial infarction. Clinical science. 2008; 115(4):133-140.

6. Ashida K, Miyazaki K, Takayama E, Tsujimoto $\mathrm{H}$, Ayaori M, Yakushiji T, Iwamoto N, Yonemura A, Isoda K, Mochizuki H, Hiraide H, Kusuhara M and Ohsuzu F. Characterization of the expression of TLR2 (toll-like receptor 2) and TLR4 on circulating monocytes in coronary artery disease. Journal of atherosclerosis and thrombosis. 2005; 12(1):53-60.

7. Versteeg D, Hoefer IE, Schoneveld AH, de Kleijn DP, Busser E, Strijder C, Emons M, Stella PR, Doevendans PA and Pasterkamp G. Monocyte toll-like receptor 2 and 4 responses and expression following percutaneous coronary intervention: association with lesion stenosis and fractional flow reserve. Heart. 2008; 94(6):770-776.

8. Liu X, Zhou P, Fan F, Li D, Wu J, Lu Y and Luo Y. CpG site methylation in CRYAA promoter affect transcription factor Sp1 binding in human lens epithelial cells. BMC ophthalmology. 2016; 16:141.

9. Zhang J, Fu B, Zhang X, Zhang L, Bai X, Zhao X, Chen L, Cui L, Zhu C, Wang L, Zhao Y, Zhao T and Wang $\mathrm{X}$. Bicyclol upregulates transcription factor Nrf2, HO-1 expression and protects rat brains against focal ischemia. Brain research bulletin. 2014; 100:38-43.

10. Vangsted AJ, Nielsen KR, Klausen TW, Haukaas E, Tjonneland A and Vogel U. A functional polymorphism in the promoter region of the IL1B gene is associated with risk of multiple myeloma. British journal of haematology. 2012; 158(4):515-518.

11. Di Marco S, Hel Z, Lachance C, Furneaux H and Radzioch D. Polymorphism in the 3'-untranslated region of TNFalpha mRNA impairs binding of the post-transcriptional regulatory protein HuR to TNFalpha mRNA. Nucleic acids research. 2001; 29(4):863-871.

12. Zhang Q, Qian FH, Zhou LF, Wei GZ, Jin GF, Bai JL and Yin KS. Polymorphisms in toll-like receptor 4 gene are associated with asthma severity but not susceptibility in a Chinese Han population. Journal of investigational allergology \& clinical immunology. 2011; 21(5):370-377.

13. Minmin S, Xiaoqian X, Hao C, Baiyong S, Xiaxing D, Junjie X, Xi Z, Jianquan Z and Songyao J. Single nucleotide polymorphisms of Toll-like receptor 4 decrease the risk of development of hepatocellular carcinoma. PloS one. 2011; 6(4):e19466.

14. Peng D, Jiang F, Zhang R, Tang S, Chen M, Yan J, Sun X, Luo Y, Hu C and Jia W. Association of Toll-like Receptor 4 Gene polymorphisms with susceptibility to type 2 diabetes mellitus in the Chinese population. Journal of diabetes. 2015; 7(4):485-492.

15. Sasu S, LaVerda D, Qureshi N, Golenbock DT and Beasley D. Chlamydia pneumoniae and chlamydial heat shock protein 60 stimulate proliferation of human vascular smooth muscle cells via toll-like receptor 4 and p44/p42 mitogenactivated protein kinase activation. Circulation research. 2001; 89(3):244-250.

16. Watari M, Watari H, Nachamkin I and Strauss JF. Lipopolysaccharide induces expression of genes encoding pro-inflammatory cytokines and the elastin-degrading enzyme, cathepsin S, in human cervical smooth-muscle cells. Journal of the Society for Gynecologic Investigation. 2000; 7(3):190-198.

17. Vink A, Schoneveld AH, van der Meer JJ, van Middelaar BJ, Sluijter JP, Smeets MB, Quax PH, Lim SK, Borst C, Pasterkamp G and de Kleijn DP. In vivo evidence for a role of toll-like receptor 4 in the development of intimal lesions. Circulation. 2002; 106(15):1985-1990.

18. Xu XH, Shah PK, Faure E, Equils O, Thomas L, Fishbein MC, Luthringer D, Xu XP, Rajavashisth TB, Yano J, Kaul S and Arditi M. Toll-like receptor-4 is expressed by macrophages in murine and human lipid-rich atherosclerotic plaques and upregulated by oxidized LDL. Circulation. 2001; 104(25):3103-3108.

19. Smiley ST, King JA and Hancock WW. Fibrinogen stimulates macrophage chemokine secretion through tolllike receptor 4. Journal of immunology. 2001; 167(5):28872894.

20. Hishida A, Matsuo K, Goto Y, Naito M, Wakai K, Tajima $\mathrm{K}$ and Hamajima N. Combined effect of miR-146a rs2910164 G/C polymorphism and Toll-like receptor 4 $+3725 \mathrm{G} / \mathrm{C}$ polymorphism on the risk of severe gastric atrophy in Japanese. Digestive diseases and sciences. 2011; 56(4):1131-1137.

21. Castano-Rodriguez N, Kaakoush NO, Pardo AL, Goh KL, Fock KM and Mitchell HM. Genetic polymorphisms in the Toll-like receptor signalling pathway in Helicobacter pylori infection and related gastric cancer. Human immunology. 2014; 75(8):808-815.

22. Wang H, Wei Y, Zeng Y, Qin Y, Xiong B, Qin G, Li J, Hu D, Qiu X, Sooranna SR and Pinhu L. The association of polymorphisms of TLR4 and CD14 genes with susceptibility to sepsis in a Chinese population. BMC medical genetics. 2014; 15:123. 
23. Zheng SL, Augustsson-Balter K, Chang B, Hedelin M, Li L, Adami HO, Bensen J, Li G, Johnasson JE, Turner AR, Adams TS, Meyers DA, Isaacs WB, Xu J and Gronberg H. Sequence variants of toll-like receptor 4 are associated with prostate cancer risk: results from the CAncer Prostate in Sweden Study. Cancer research. 2004; 64(8):2918-2922.

24. Valencia-Sanchez MA, Liu J, Hannon GJ and Parker R. Control of translation and mRNA degradation by miRNAs and siRNAs. Genes \& development. 2006; 20(5):515-524.

25. Sato K, Yoshimura A, Kaneko T, Ukai T, Ozaki Y, Nakamura H, Li X, Matsumura H, Hara Y and Ogata Y. A single nucleotide polymorphism in 3'-untranslated region contributes to the regulation of Toll-like receptor 4 translation. The Journal of biological chemistry. 2012; 287(30):25163-25172.

26. Peppes V, Rammos G, Manios E, Koroboki E, Rokas S and Zakopoulos N. Correlation between myocardial enzyme serum levels and markers of inflammation with severity of coronary artery disease and Gensini score: a hospital-based, prospective study in Greek patients. Clinical interventions in aging. 2008; 3(4):699-710.

27. Hollestelle SC, De Vries MR, Van Keulen JK, Schoneveld AH, Vink A, Strijder CF, Van Middelaar BJ, Pasterkamp G, Quax PH and De Kleijn DP. Toll-like receptor 4 is involved in outward arterial remodeling. Circulation. 2004; 109(3):393-398.

28. Yin YW, Liao SQ, Zhang MJ, Liu Y, Li BH, Zhou Y, Chen L, Gao CY, Li JC and Zhang LL. TLR4-mediated inflammation promotes foam cell formation of vascular smooth muscle cell by upregulating ACAT1 expression. Cell death \& disease. 2014; 5:e1574.

29. Xu Y, Wang W, Zhang L, Qi LP, Li LY, Chen LF, Fang Q, Dang AM and Yan XW. A polymorphism in the ABCG1 promoter is functionally associated with coronary artery disease in a Chinese Han population. Atherosclerosis. 2011; 219(2):648-654.
30. Pollak A, Rokach A, Blumenfeld A, Rosen LJ, Resnik L and Dresner Pollak R. Association of oestrogen receptor alpha gene polymorphism with the angiographic extent of coronary artery disease. European heart journal. 2004; 25(3):240-245.

31. Gensini GG. A more meaningful scoring system for determining the severity of coronary heart disease. The American journal of cardiology. 1983; 51(3):606.

32. Mark DB, Nelson CL, Califf RM, Harrell FE, Jr., Lee KL, Jones RH, Fortin DF, Stack RS, Glower DD, Smith LR and et al. Continuing evolution of therapy for coronary artery disease. Initial results from the era of coronary angioplasty. Circulation. 1994; 89(5):2015-2025.

33. Sun D, Sun L, Xu Q, Gong Y, Wang H, Yang J and Yuan Y. SNP-SNP Interaction between TLR4 and MyD88 in Susceptibility to Coronary Artery Disease in the Chinese Han Population. International journal of environmental research and public health. 2016; 13(3).

34. Dandona S, Stewart AF, Chen L, Williams K, So D, O'Brien E, Glover C, Lemay M, Assogba O, Vo L, Wang YQ, Labinaz M, Wells GA, McPherson R and Roberts R. Gene dosage of the common variant $9 \mathrm{p} 21$ predicts severity of coronary artery disease. Journal of the American College of Cardiology. 2010; 56(6):479-486.

35. Patel RS, Su S, Neeland IJ, Ahuja A, Veledar E, Zhao J, Helgadottir A, Holm H, Gulcher JR, Stefansson K, Waddy S, Vaccarino V, Zafari AM and Quyyumi AA. The chromosome 9p21 risk locus is associated with angiographic severity and progression of coronary artery disease. European heart journal. 2010; 31(24):3017-3023. 